Erzincan Üniversitesi Sosyal Bilimler Enstitüsü Dergisi ２020-13(1)-ss/pp.93-109

Erzincan University Journal of Social Sciences Institute

E-ISSN-2148-9289

\title{
COVID-19 Salgınının Altın Fiyatları, Petrol Fiyatları ve VIX Endeksi ile Arasındaki İlişki
}

\author{
The Relationship of COVID-19 Pandemic with Gold Prices, Oil Prices and VIX \\ Index
}

Arş. Gör. Dr. Salim Sercan SARI, Arş. Gör. Taha KARTAL

Atıf/O: Sarı, Salim Sercan; Kartal, Taha (2020). COVID-19 Salgınının Altın Fiyatları, Petrol Fiyatları ve VIX Endeksi ile Arasındaki İlişki, Erzincan Üniversitesi Sosyal Bilimler Enstitüsü Dergisi, Y1l 13, Say1 1, ss. 93-109

Citation/C: Sar1, Salim Sercan; Kartal, Taha (2020). The Relationship of COVID-19 Pandemic with Gold Prices, Oil Prices and VIX Index, Erzincan University Journal of Social Sciences Institute, Year 13, Issue 1, pp.93-109

\section{Notlar/Notes}

DOI:

10.46790/erzisosbil.748181

Orcid:

http:/0000-0003-2607-5249

Salim Sercan SARI

Erzincan Binali Y1ldırım

Üniversitesi, İIBF, İşletme Bölümü

$\underline{\text { salim.sari@erzincan.edu.tr }}$

Orcid:

http:/0000-0002-8491-8446

Taha KARTAL

Erzincan Binali Yıldırım

Üniversitesi, IİBF, Bankacılık ve

Finans Bölümü

$\underline{\text { taha.kartal@erzincan.edu.tr }}$

Makale Türü-Article Type

Araștırma/Research

Geliș Tarihi-Received

04.06.2020

Kabul Tarihi-Accepted

25.06.2020

Sayfa-Pages

93-109

Yazar(lar), herhangi bir çıkar çatışması beyan etmemiştir.
Öz:

COVID-19 salgını döneminde oluşan korku ve belirsizlik finansal piyasalarda ve emtia piyasalarında oynaklığın artışına neden olmuştur. Bu çalışma COVID-19'un finansal piyasalar ve emtia piyasaları üzerinde önemli etkilerinin olduğunu göstermek amacıyla yapılmıştır. 22 0cak 2020 ve 20 Nisan 2020 dönemi dikkate alınmış ve günlük veriler kullanılarak analiz gerçekleştirilmiştir. COVID-19 günlük vaka sayılarının, ARDL Sınır Testi kullanılarak altın fiyatları, petrol fiyatları ve VIX Endeksi üzerindeki muhtemel etkisi incelenmiştir. Ulaşılan sonuçlara göre vaka sayıları ve altın fiyatları arasında aynı yönlü ilişki tespit edilmiştir. Benzer şekilde vaka sayıları ve VIX Endeksi arasında da aynı yönlü bir ilişki tespit edilmiştir. Ancak vaka sayıları ve petrol fiyatları arasında herhangi bir eş bütünleşme ilişkisi tespit edilememiştir. Çalışmada ulaşılan sonuçlar, COVID-19 vaka sayılarının altın fiyatları ve VIX Endeksini önemli derecede etkilediğini göstermiştir.

Anahtar Kelimeler: COVID-19 Salgını, Altın Fiyatları, Petrol Fiyatları, VIX Endeksi.

\begin{abstract}
:
Fear and uncertainty during the COVID-19 epidemic have caused an increase in volatility in financial markets and commodity markets. This study was carried out to show that COVID-19 has significant effects on financial markets and commodity markets. The analysis was carried out using daily data by taking into consideration the period between 22 January 2020 and 20 April 2020. The possible impact of COVID-19 daily case numbers on gold prices, oil prices and the VIX Index was analyzed using the ARDL Limit Test. According to the results reached in thi study, a similar relationship was observed between the number of cases and gold prices. Correlatively, a similar relationship was found between the number of cases and the VIX Index. However, no cointegration relationship could be determined between the number of cases and oil prices. The results obtained in the study showed that the number of COVID-19 cases significantly affected the gold prices and VIX Index.

Keywords: COVID-19 Pandemic, Gold Prices, Oil Prices, VIX Index.
\end{abstract}




\section{GíRiş}

Dünya 2019 Aralık ayından beri COVID-19 salgın hastalığıyla çeşitli tedbirler alarak mücadele etmektedir. Bu salgın hastalıktan etkilenen nüfus sayısı her geçen gün artmakta ve virüsün kontrol altına alındığına ilişkin herhangi bir bulguya rastlanılmamaktadır. COVID-19 salgın hastalığından önce de yakın tarihe bakıldığında 20. ve 21. yüzyılda dünya genelinde salgın hastalıkların örnekleri bulunmaktadır. 1918 yılında İspanyol Gribi, 1957 yılında Asya Gribi ve 1968 yılında Hong Kong Gribi 20. yüzyılda yaşanan hastalıklardır. 21. yüzyılda ise dünya salgın hastalıklara 2002 yılında yaşanan Şiddetli Akut Solunum Sendromu (SARS) ile tanık olmuştur. Sonrasında 2009 yılında Kuş Gribi ve 2012 yılında Orta Doğu Solunum Sendromu (MERS) salgın hastalıklarını yaşamıştır. Son olarak ise 2019 Aralık ayında Çin'in Hubei eyaletindeki Wuhan şehrinde görülen COVID-19 salgını ortaya çıkmıştır. Salgının başlangıç noktası Çin olmasına rağmen birçok ülkeden vakalar bildirilmektedir. Etkili bir şekilde tedavi edilen vakaların sayısı artsa da diğer taraftan yeni vakaların nerede ve ne zaman ortaya çıkacağı hakkındaki belirsizlik devam etmektedir. Hızlı bir şekilde yayılan ve 200.000' e yakın insanın hayatını kaybetmesine neden olan hastalığın meydana getirdiği panik ve korkunun büyüdüğü görülmektedir. 21. yüzyılın en kötü sağlık krizinin yaşanmasına neden olan COVID19 salgın hastalığı 11 Mart 2020'de Dünya Sağlık Örgütü tarafından salgın hastalık olarak ilan edilmiştir.

Salgının yoğun görüldüğü ülkelerde insanlar evden çalışmaya teşvik edilmekte, zorunlu olmadıkça dışarı çıkmamaları için öneriler ve yasaklarla COVID-19 salgın hastalığının yayılması önlenmeye çalışılmaktadır. Bunun sonucunda alışveriş merkezleri, kafeler, restoranlar, oteller, seyahat, eğitim ve benzeri işletmelerin gelirlerinde büyük düşüş yaşanmaktadır. İş toplantılar, sempozyumlar, konferanslar, toplu organizasyonlar ve tatiller iptal edilmektedir. Tedarik zincirlerinde sıkıntılar yaşanmakta ve birçok sektörde üretim devam etmemektedir. Küresel bazda hızlı ve karmaşık bir şekilde gelişen bu salgın ve beraberinde getirdiği olumsuzluklar finansal piyasaları çıkmaza sürüklemektedir.

COVID-19 onlarca ülkede hızlı bir şekilde hızla yayılmaya devam etmektedir. 27 Nisan 2020 tarihi itibariyle 180'den fazla ülkede 3 milyonu aşkın onaylanmış COVID-19 vakası ve 211449 ölüm vakası bulunmaktadır. Bu tarih itibariyle COVID-19'dan en çok etkilenen ilk on ülkenin sırasıyla ABD, İspanya, İtalya, Fransa, Almanya, Birleşik Krallık, Türkiye, İran, Çin ve Rusya olduğu görülmektedir (worldometers). Dünyanın en büyük ekonomilerinin yer aldığı bu sıralamaya bakılırsa COVID-19'un makroekonomik etkilerinin önemli olacağı tahmin edilebilmektedir. Vakalar ve ölüm sayılarının katlanarak artmasıyla orantılı olarak ekonomik kayıplarında arttığı görülmektedir. Dünyanın dört bir yanında insanlar COVID-19 nedeniyle hayati tehlike altında olmaları yetmezmiş gibi ekonomik problemler yaşamaktadırlar.

Finansal piyasaları yönlendiren en önemli faktörlerden birinin insan davranışları olduğu düşünülmektedir. Insanlar ise COVID-19 salgını nedeniyle davranışsal değişim yaşamaktadırlar. Artan belirsizliğe insanların ne şekilde tepki vereceği ve nasıl tedbirler alacağı bilinmediğinden finansal piyasalarda dalgalanmalar meydana gelmektedir. COVID-19 salgınının sadece sağlık sorunu değil ciddi finansal sorunlar oluşturacağına odaklanılmaktadırlar. Buradan hareketle finansal aktörler dünya çapında finansal sistemi etkileyen göstergelere bakarak doğru karar vermeye çalışmaktadırlar. Söz konusu göstergeler içerisinde hisse senedi piyasası, emtiya piyasası, döviz kurları ve benzeri yer almaktadır.

Yüksek likiditeye sahip altın ve petrol fiyatlarının dünya çapında bir finansal etkiye sahip olduğu bilinmektedir. Bu iki yatırım aracı finansal piyasalarda benzer hareket etmektedirler. 
Geçmişten bugüne yaşanan finansal kriz dönemlerinde altın finansal aktörler tarafından güvenli liman olarak görülmüş ve yatırımcılarına kazanç sağlamıştır. COVID-19 salgını döneminde de altın ve petrol fiyatlarında önemli değişimler yaşanmıştır.

Küresel finans piyasalarındaki hareketleri tahmin etmek için finansal aktörlere yardımcı göstergelerden bir diğeri de Şikago Opsiyon Borsası Volatilite Endeksidir. ABD finansal piyasaları için öncü gösterge niteliğinde olan VIX Endeksi S\&P 500 endeksini içine alan 30 gün vadeli opsiyonların volatilitelerinden meydana gelmektedir. 1993 yılından beri hesaplanan ve piyasa göstergesi olarak piyasa katılımcıları tarafından yakından izlenen volatilite ölçümlerinden biridir.

Bu çalışma 22 Ocak 2020 tarihinden itibaren COVID-19 salgın hastalığının altın ile petrol ve VIX Endeksi üzerindeki etkisini ARDL Sınır Testi yöntemi ile göstererek tüm dünya için zor zamanların yaşandığı bu süreçte finansal piyasa aktörlerine yol göstermek için kanıtlar sunmayı amaçlamaktadır.

\section{LITERATÜR ARAŞTIRMASI}

Bu bölümde öncelikle 20. ve 21. yüzyılda dünya üzerinde yaşanan diğer salgınlardan ve sonrasında COVID-19 salgını süresince yaşanan benzer çalışmalardan bahsedilmektedir.

Bloom ve Mahal (1997) çalışmalarında AIDS salgınının ekonomik büyüme hızını yavaşlatacağı iddiasını incelemişlerdir. 51 gelişmekte olan ve sanayi ülkesinde, AIDS prevalansındaki değişiklikler ile kişi başına GSYiH büyüme oranı arasındaki değişikliğe ampirik olarak bakmışlardır. AIDS salgınının kişi başına gelirin büyüme hızı üzerinde ters nedensellik kanıtı olmadan önemsiz bir etkisi olduğunu tespit etmişlerdir.

Baldwin ve Tomiura (2000) çalışmalarında uluslararası mal ve hizmet ticaretini etkileyen COVID-19'un geleceğe yönelik çabayı yönlendirmek için tarih ve ekonomik mantığı kullanarak ticaretin etkileri üzerinde düşünmeye yönelik bir girişimde bulunmuşlardır. Ticaret sisteminde politika ve firmaların tepkileri nedeniyle kalıcı hasar tehlikesi olduğunu belirtmişlerdir. ABD'nin Çin ve diğer ticaret ortaklarına karşı devam eden ticaret savaşının ve COVID-19'un yol açması muhtemel tedarik zinciri aksamalarının birleşimi, tedarik zincirlerinin ülkelerine geri gönderilmesine yol açabileceğini sunmuşlardır. Doğrudan yabancı yatırım hedeflerini çeşitlendirmenin firmaların küresel kaynak kullanımını daha etkin bir şekilde koordine edeceği sonucuna ulaşmışlardır.

Brown ve Smith (2008) çalışmalarında 2003 SARS salgınının makroekonomik etkisinin retrospektif bir analizini yapmışlardır. Analizlerinde, etkilenen ekonomiler üzerindeki SARS etkisinin ölçeğinin çağdaş medya raporları ve model tahminleri tarafından önerilenden çok daha küçük olduğunu göstermişlerdir. Uluslararası endişe salgınlarına karşı küresel bir yanıtın göreceli maliyetini ve etkisini daha doğru bir şekilde tahmin edebilecek kapsamlı makroekonomik model geliştirmek için daha fazla çalışmaya ihtiyaç olduğunu önermişlerdir.

Beutels vd. (2009) çalışmada Pekin'deki şiddetli akut solunum sendromu (SARS) salgınının sosyal ve ekonomik faaliyet göstergeleri üzerindeki etkisini belgelemişlerdir. Pekin'de günlük ve aylık SARS vakalarının zaman serileri ile halk treni, uçak ve yük taşımacılığı, turizm, hanehalkı tüketim alışkanlıkları ve gayri safi yurtiçi hasıla ölümleri ile hacmi arasındaki ilişkiler çapraz korelasyon fonksiyonu kullanılarak araştırılmıştır. Pekin'de günlük ve aylık SARS vakalarının ölümlerinin zaman serileri ile banliyö treni, uçak ve yük taşımacılığı, turizm, hanehalkı tüketim alışkanlıkları ve gayri safi yurtiçi hasıla büyümesi arasındaki ilişkiler çapraz korelasyon fonksiyonu kullanılarak araştırılmıştır. Özellikle boş zaman etkinlikleri, yerel ve 
uluslararası taşımacılık ve turizm SARS'dan en çok Mayıs 2003'te etkilenmiştir. Ancak sadece turizm sektöründe kayıpların Pekin'deki SARS vakaları için tedavi maliyetinin yaklaşık 1.4 milyar dolar veya tedavi maliyetinin 300 katı olduğu belirtilmiştir.

Açıkgöz ve Günay (2020) çalışmalarında hem dünya hem de Türkiye için açıklanan verilere göre maliyetlerini değerlendirerek salgının sektörler aracılığıyla kısa ve uzun vadeli küresel ekonomik etkilerinin potansiyel ilk tepkilerini tartışmayı amaçlamışlardır. COVID-19'un ekonomik sonuçları hakkındaki mevcut raporları ve tartışmaları özetleyerek ve bunları dikkate alarak bazı çıkarımlar yapmaya çalışmışlardır. Bulgularda COVID-19'un çalışanlar, müşteriler, tedarik zincirleri ve finansal piyasalar üzerinde ciddi olumsuz etkileri olduğu görülmüştür. Bu pandeminin sonunun belirsizliği nedeniyle, bu kasılmanın hem uzunluğunun hem de ölçeğinin tahmin edilemeyeceğini söylemişlerdir.

Albulescu (2020a) çalışmasında COVID-19 rakamlarının ham petrol fiyatları üzerindeki etkisini araştırırken finansal oynaklığın ve $A B D$ ekonomi politikası belirsizliğinin etkisini kontrol etmeyi amaçlamıştır. ARDL tahmini ile, COVID-19'un günlük rapor edilen yeni enfeksiyon vakalarının uzun vadede ham petrol fiyatları üzerinde marjinal bir olumsuz etkiye sahip olduğunu göstermiştir.

COVID-19 ile ilgili bir başka çalışmasında Albulescu (2020b) COVID-19'un uluslararası izlenmesinin başlamasından 40 gün sonra, yeni enfeksiyon ve ölüm oranlarına ilişkin resmi açıklamaların finansal piyasaların oynaklık endeksi (VIX) üzerindeki etkisini araştırmıştır. Bulgularda Çin'de ve Çin dışında bildirilen yeni vakaların finansal oynaklık üzerinde karışık bir etkisi olmasına rağmen, ölüm oranı VIX'i olumlu etkilemiştir. Çin dışında daha önemli bir etkiyi tetiklemiştir. Son olarak etkilenen ülke sayısı arttıkça finansal oynaklık da artmıştır.

Baker vd. (2020) çalışmalarında COVID-19 gelişmelerinin ABD'de son borsa davranışındaki rolünü ele almış ve önceki bulaşıcı hastalık salgınlarıyla karşılaştırmalar yapmışlardır. Bulaşıcı hastalık salgınları hakkındaki haberlerin rolünü ölçmek için otomatik veri ve insani gazete makalelerini okumuşlardır. 1985 'e baktığımızda, ABD borsa oynaklığı üzerinde çok küçük bir etkisi olan başka bulaşıcı hastalık salgını bulamamışlardır. 1900 yılına ve son olarak dünya nüfusunun yaklaşık yüzde 2'sini öldüren 1918-20 İspanyol Gribine baktıklarında çağdaş gazete hesaplarının büyük bir günlük piyasanın pandemi ile ilgili gelişmelere atfettiği tek bir örnek bulamamışlardır. Ancak COVID-19 gelişmeleri ile ilgili haberlerin ezici bir çoğunlukla 24 Şubat 2020 'den bu yana büyük günlük $A B D$ borsa hareketlerinin baskın itici gücü olduğunu tespit etmişlerdir.

Beck (2020) çalışmasında COVID-19 nedeniyle küresel finansal sistem veya küresel ekonomi üzerinde önümüzdeki aylarda neler olabileceği konusunda fikirler vermiştir. Finansal sistemdeki olası operasyonel aksaklıklara odaklanmak, müdahale etmeye hazır olduklarını açıkça göstererek finansal piyasalara olan güveni güçlendirmek ve kuyruk riski olaylarını göz ardı etmeden, başarısız bankaların olası müdahalelerine ve çözümlerine hazırlanmak gibi tavsiyelerde bulunmuşlardır.

Eichenbaum vd. (2020) çalışmalarında ekonomik kararlar ile salgın hastalıklar arasındaki etkileşimi incelemek için kanonik epidemiyoloji modelini genişletmişlerdir. Model, insanların tüketimi ve işi azaltma kararının, toplam ölümlerle ölçülen salgının şiddetini azalttığını vurgulamaktadır. Bu kararlar salgının yol açtığı durgunluğun büyüklüğünü artırmaktadır. Kıyaslama modelinde, en basit sınırlama politikası durgunluğun şiddetini arttırdığını, ancak $A B D$ 'de yaklaşık yarım milyon hayat kurtardığını belirtmişlerdir. 
Erik vd. (2020) çalışmalarında COVID-19 sürecinde Küresel Satın Alma Yöneticileri Endeksleri, dünya ticareti ve küresel finansal koşullarının göstergeleri arasındaki ampirik ilişkiyi, geniş dolar endeksine odaklanarak incelemişlerdir. Doların reel ekonomik aktivite ve küresel ticaret üzerindeki etkisinin GSYiH'dan bu yana arttığını, VIX'in ise azaldığını göstermişlerdir.

Luo ve Tsang (2020) çalışmalarında bir ağ yaklaşımı kullanarak, COVID-19 tarafından tetiklenen Hubei eyaletinin kilitlenmesi nedeniyle üretim kaybını tahmin etmişleridir. Çin'in işgücü kaybından yaklaşık \% 4 üretim kaybı yaşadığını ve küresel üretimin, Çin'deki ekonomik daralma nedeniyle dönem başına\% 1 azaldığını belirtmişlerdir. Etkinin yaklaşık \% 40'ının dolaylı olduğunu, Çin içindeki ve dışındaki tedarik zincirindeki yayılmalardan kaynaklandığı sonucuna ulaşmışlardır.

Makridlis ve Hartley (2020)'ye göre geleneksel makroekonomik göstergelerin, yeni koronavirüs nedeniyle ekonomik yavaşlamanın büyüklüğü hakkında anlamlı bilgiler vermesi zaman alacaktır. Bu nedenle kabul edilen etki azaltma dereceleri, toplum için ağır bir maliyet getirecektir. Çalışmada söz konusu boşluğu doldurmak için, mevcut azaltma derecelerinin 2020 GSYiH büyüme oranı üzerindeki etkisini sunmuşlardır. Reel GSYiH büyüme oranının, kısmi ekonomik kapanışın her ayı için yüzde 5 düşeceğini tahmin etmişlerdir. Bu nedenle, pandemi ile savaşan ilk iki ayın ekonomik maliyeti 2,14 trilyon dolar olacağını belirtmişlerdir.

Onali (2020) çalışmasında COVID-19 vakalarının ve ilgili ölümlerin ABD borsası üzerindeki etkisini inceleyerek işlem hacminde ve oynaklık beklentilerinde değişikliklerin yanı sıra haftanın günü etkilerini de araştırmıştır. Sonuç olarak, COVID-19 krizinden büyük ölçüde etkilenen $A B D$ ve diğer altı ülkedeki vaka ve ölüm sayısındaki değişikliklerin, Çin için bildirilen vaka sayısı dışında $A B D$ borsa getirileri üzerinde bir etkisi olmadığını göstermiştir. VAR modelleri ile, İtalya ve Fransa'da bildirilen ölüm sayısının borsa getirileri üzerinde olumsuz etkisi olduğunu ve VIX getirileri üzerinde olumlu bir etkisi olduğunu göstermiştir. MarkovSwitching modelleri ile Şubat 2020'nin sonunda VIX'in borsa getirileri üzerindeki olumsuz etkisinin büyüklüğünün üç kat arttığını göstermiştir.

Özatay ve Sak (2020) COVID-19'la mücadelede ekonomik olarak ne yapılabileceğini kavramsal çalışmalarıyla açıklamışlardır. Bu tür küresel sıkıntılarda olayların tamamlanmasını beklemenin ve ondan sonra iktisadi hayatın yeniden canlandırılmasına odaklanmanın doğru olacağını, işletmeleri salgının farkına vardırarak ticari faaliyetlerine devam etmelerinin doğru olacağını belirtmişlerdir. Son olarak küresel salgının olası iktisadi etkilerini hızla yönetebilmek için doğru tedbirler alınmasının süreci kolaylaştıracağını dile getirmişlerdir.

Şenol ve Zeren (2020) çalışmalarında 21 Ocak 2020 ve 7 Nisan 2020 tarihleri arasında COVID-19 salgınının küresel pazarlar üzerindeki etkisini araştırmışlardır. Küresel pazarları ise Morgan Stanley Capital International (MSCl) 'World, gelişmekte olan pazar, Avrupa ve G7 endeksleri tarafından temsil etmişlerdir. Fourier Eşbütünleşme testi ile yapılan analizde, hisse senedi piyasaları ile COVID-19 arasında uzun vadeli bir ilişki olduğunu belirtmişlerdir.

Zeren, Hızarcı (2020) bu çalışmada, COVID-19 salgınının borsalar üzerindeki olası etkilerini ortaya koymayı amaçlanmışlardır. Analizde hem COVID-19 günlük ölüm ve vaka sayılarının, eşbütünleşme testi kullanılarak borsalar üzerindeki olası etkilerini araştırmışlardır. Sonuçta toplam ölümle incelenen tüm borsaların uzun vadede birlikte hareket ettiğini göstermişlerdir. Toplam vakaların SSE, KOSPI ve IBEX35 ile eşbütünleşme ilişkisi içerisinde olduğu ve bu vakaların FTSE MIB, CAC40, DAX30 ile eşbütünleşik olmadığını belirtmişlerdir. Yatırımcıların borsa yatırımlarından kaçınmalarını, altın piyasalarına yönelmelerinin uzun 
vadede en uygun seçeneklerden biri olduğunu göstermişlerdir. Ayrıca, sanal para birimlerine yönelmeyi de başka bir seçenek olarak sunmuşlardır.

\section{METODOLOJi}

Çalışmada kullanılmış olan COVID-19 verileri worldometer.com ve investing.com sitelerinden günlük veri setleri olarak elde edilmiştir. Veri seti ise verilere ulaşabildiğimiz tarih olan 22 Ocak 2020 ve 20 Nisan 2020 dönemini kapsamaktadır. Altın fiyatlarını temsilen Ons altın ve petrol fiyatlarını temsilen Brent Petrol fiyatları kullanılmıştır. Çalışmada değişkenler arasındaki ilişkiye bakmak için kurulan modeller (3.1), (3.2) ve (3.3) numaralı eşitliklerde gösterilmiştir.

$$
\begin{aligned}
& \ln A F_{t}=a_{0}+a_{1} \ln C V D_{t}+u_{t} \\
& \ln P F_{t}=a_{0}+a_{1} \ln C V D_{t}+u_{t} \\
& \ln V I X_{t}=a_{0}+a_{1} \ln C V D_{t}+u_{t}
\end{aligned}
$$

(3.1), (3.2) ve (3.3) numaralı denklemlerde InAF altın fiyatlarının logaritmasını, InPF petrol fiyatlarının logaritmasını, InVIX VIX endeksinin logaritmasını ve InCVD COVID-19 vaka sayılarının logaritmasını temsil etmektedir.

Zaman serisi analizlerinde öncelikle veri setlerinin durağanlıklarına bakılır. Serilerin farklı derecelerde durağan olduğu durumlarda Engle-Granger ve Johansen eşbütünleşme testleri kullanılması uygun değildir. Bu sorunu gidermek için Pesaran ve Shin (1998) ve Pesaran vd. (2001) farklı derecelerde durağan olan seriler arasında eşbütünleşme ilişkisine bakmaya yarayan bir ekonometrik yöntem önermişlerdir.

ARDL yöntemi, değişkenlerin I(0) veya I(1) olarak kullanılabilmesine imkân tanır ancak, değişkenlerin I(2) olmamaları gerekmektedir. Bunun nedeni, değişkenlerin I(2) düzeyinde entegre olmaları durumunda $\mathrm{F}$ istatistiklerinin geçersiz olmasıdır. Bu açıdan, birim kök testleri yapılarak değişkenlerin durağanlıklarının kontrol edilmesi önemlidir (Fosu ve Mangus, 2006: 2082).

Gecikmesi dağıtılmış otoregresif model $\operatorname{ARDL}(p, q),(2.4)$ numaralı denklemde görüldüğü gibi ifade edilebilir.

$Y_{t}=c_{0}+c_{1} t+\sum_{i=0}^{p} \delta_{i} y_{t-i}+\sum_{i=0}^{q} \beta_{i} x_{t-i}+u_{t}$

ARDL sınır testi yapılırken (3.5), (3.6) ve (3.7) numaralı hata düzeltme modelleri tahmin edilmektedir.

$$
\begin{aligned}
& \Delta \ln A F_{t}=\delta_{0}+\sum_{i=1}^{k} a_{1} \Delta \ln A F_{t-i}+\sum_{i=0}^{k} a_{2} \Delta \ln C V D_{t-i}+\delta_{1} \ln A F_{t-1}+\delta_{2} \ln C V D_{t-1}+\varepsilon_{1 t} \\
& \Delta \ln P F_{t}=\delta_{0}+\sum_{i=1}^{k} a_{1} \Delta \ln P F_{t-i}+\sum_{i=0}^{k} a_{2} \Delta \ln C V D_{t-i}+\delta_{1} y_{t-1}+\delta_{2} \ln C V D_{t-1}+\varepsilon_{1 t} \\
& \Delta \operatorname{lnVIX} X_{t}=\delta_{0}+\sum_{i=1}^{k} a_{1} \Delta \operatorname{lnVIX_{t-i}}+\sum_{i=0}^{k} a_{2} \Delta \operatorname{lnCVD_{t-i}}+\delta_{1} y_{t-1}+\delta_{2} \ln C V D_{t-1}+\varepsilon_{1 t}
\end{aligned}
$$


(3.5), (3.6) ve (3.7) numaralı eşitliklerde, $\Delta$ fark operatörünü, k gecikme sayısını göstermektedir. $\varepsilon_{1 t}$ ise bağımsız rassal hatayı göstermektedir.

ARDL sınır testi uygulanırken önce (3.5), (3.6) ve (3.7) numaralı modelde " $k$ " olarak gösterilen gecikme uzunlukları belirlenmektedir. Model için en uygun gecikme uzunlukları belirlenirken AIC, HQ, SBC gibi bilgi kriterlerinden yararlanılarak, en küçük kritik değeri sağlayan gecikme uzunluğu seçilmektedir. Bu işlemlerden sonra uzun dönemli ilişkinin bulunmadığını ifade eden $H_{0}=\delta_{1}=\delta_{2}=0$ şeklindeki boş hipotez, $H_{1} \neq \delta_{1} \neq \delta_{2} \neq 0$ alternatif hipotezine karşı test edilir. Hesaplanan F istatistik değeri, Pesaran vd. (2001)'nin çalışmalarında verilen alt ve üst kritik değerler ile karşılaştırılır. Hesaplanan $\mathrm{F}$ istatistiği alt kritik değerin altındaysa $\mathrm{H}_{0}$ hipotezi reddedilemez. Eğer $\mathrm{F}$ istatistiği üst kritik değerin üstündeyse $\mathrm{H}_{0}$ hipotezi reddedilerek seriler arasında eşbütünleşme ilişkisinin olduğuna karar verilir. Hesaplanan $F$ istatistiğinin alt ve üst kritik değerlerinin arasında olması durumunda ise değişkenler arasındaki eşbütünleşme hakkında kesin bir yorum yapılamamaktadır (Taban, 2008: 157).

Sınır testi analizi yaparak uzun ve kısa dönem katsayılarının da hesaplanması mümkündür. Değişkenler arasındaki uzun dönem ilişkisinin tahmininde kullanılan, gecikmesi dağıtılmış otoregresif model (ARDL) (3.8), (3.9) ve (3.10) numaralı eşitliklerde gösterilmiştir (Bardsen, 1989: 346):

$$
\begin{aligned}
& \ln A F_{t=} \delta_{0}+\sum_{i=1}^{k} a_{1} \ln A F_{t-i}+\sum_{i=0}^{l} a_{2} \ln C V D_{t-i}+\varepsilon_{t} \\
& \ln P F_{t=} \delta_{0}+\sum_{i=1}^{k} a_{1} \ln P F_{t-i}+\sum_{i=0}^{l} a_{2} \ln C V D_{t-i}+\varepsilon_{t} \\
& \ln V I X_{t=} \delta_{0}+\sum_{i=1}^{k} a_{1} \ln V I X_{t-i}+\sum_{i=0}^{l} a_{2} \ln C V D_{t-i}+\varepsilon_{t}
\end{aligned}
$$

Kısa dönem ilişkisinin tespitinde kullanılan tahmin modelleri ise (3.11), (3.12) ve (3.13) numaralı eşitliklerde gösterilmiştir.

$$
\begin{aligned}
& \Delta \ln A F_{t=} \delta_{0}+a_{0} E C_{t-1}+\sum_{i=1}^{k} a_{1} \Delta \ln A F_{t-i}+\sum_{i=0}^{l} a_{2} \Delta \operatorname{lnCV} D_{t-i}+\varepsilon_{t} \\
& \Delta \ln P F_{t=} \delta_{0}+a_{0} E C_{t-1}+\sum_{i=1}^{k} a_{1} \Delta \ln P F_{t-i}+\sum_{i=0}^{l} a_{2} \Delta \ln C V D_{t-i}+\varepsilon_{t} \\
& \Delta \operatorname{lnVIX} X_{t=} \delta_{0}+a_{0} E C_{t-1}+\sum_{i=1}^{k} a_{1} \Delta \operatorname{lnVIX} X_{t-i}+\sum_{i=0}^{l} a_{2} \Delta \operatorname{lnCV} D_{t-i}+\varepsilon_{t}
\end{aligned}
$$

Eşitlik (3.11), (3.12) ve (3.13)'de $E C_{t-1}$ hata düzeltme terimini göstermektedir. $E C_{t-1}$ hata düzeltme terimi kısa dönemde meydana gelen sapmaların ne kadarlık bir kısmının, bir sonraki dönemde düzeltileceğini belirtmektedir. Bu terimin katsayısının negatif ve istatistiki olarak anlamlı olması beklenmektedir.

Çalışmanın ilk aşamasında serilerin durağan olup olmadıklarını incelemek için Eviews paket programı aracılı̆ıyla, Augmented Dickey-Fuller (ADF) ve Phillips-Perron (PP) birim kök testlerinden yararlanılmıştır. 


\begin{tabular}{|c|c|c|c|c|}
\hline YÖNTEM & \multicolumn{2}{|c|}{ ADF } & \multicolumn{2}{c|}{ PP } \\
\hline DEĞiŞKENLER & Sabitli & $\begin{array}{c}\text { Sabitli ve } \\
\text { Trendli }\end{array}$ & Sabitli & $\begin{array}{c}\text { Sabitli ve } \\
\text { Trendli }\end{array}$ \\
\hline LNAF & -1.698 & -2.084 & -2.049 & -2.463 \\
\hline$\Delta$ LNAF & $-6.374^{*}$ & $-6.329^{*}$ & $-6.374^{*}$ & $-6.328^{*}$ \\
\hline LNVIX & -1.456 & -1.082 & -1.456 & -1.114 \\
\hline$\Delta$ LNVIX & $-9.413^{*}$ & $-9.571^{*}$ & $-9.241^{*}$ & $-9.376^{*}$ \\
\hline LNPF & -0.726 & -1.618 & -0.768 & -1.811 \\
\hline$\Delta$ LNPF & $-6.765^{*}$ & $-6.703^{*}$ & $-6.765^{*}$ & $-6.703^{*}$ \\
\hline LNCVD & 0.537 & $-3.185^{* * *}$ & $-3.725^{*}$ & $-5.194^{*}$ \\
\hline$\Delta$ LNCVD & $-3.480^{* *}$ & $-4.409^{*}$ & $-4.861^{*}$ & $-5.413^{*}$ \\
\hline
\end{tabular}

$*, * *$ ve ${ }^{* * *}$ serilerin birim kök içerdiği $\mathrm{H}_{0}$ hipotezinin sırasıyla $\% 1, \% 5$ ve $\% 10$ seviyelerinde reddedildiğini gösterir.\%1, \%5 ve \%10 kritik değerleri sırasıyla, sadece sabit içeren model için $-3.54,-2.91$ ve -2.59 'dir, sabit ve trend içeren model için $-4.11,-3.48$ ve -3.17 'tür. $\Delta ; 1$. fark operatörünü göstermektedir.

Tablo 1'e bakıldığında altın fiyatları, petrol fiyatları ve VIX endeksi serilerinin birinci farkları alındığında durağan hale geldikleri görülürken, COVID-19 vaka sayısı serisinin düzey değerinde durağan olduğu görülmektedir. Bu nedenle çalışmada ARDL Sınır testi yönteminin kullanılması uygun görülmüştür.

Akaike Bilgi Kriteri

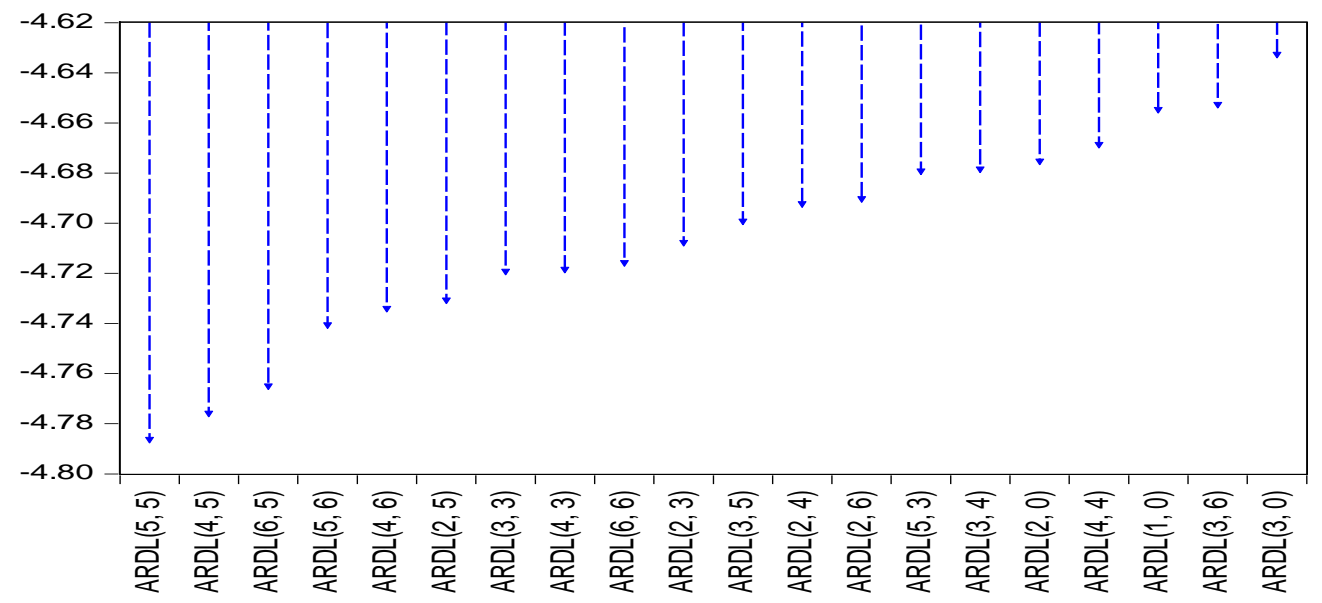

Şekil 1. Altın Fiyatları - COVID-19 Modeli İçin Uygun Gecikme Uzunluğu

Şekil 1'e göre Akaike bilgi kriteri değeri en düşük olan ARDL $(5,5)$ modeli en uygun model olarak belirlenmiştir.

Gecikme uzunlukları belirlendikten sonra 3.5 numaralı eşitlik yardımıyla Sınır Testi analizi yapılmıştır. Analiz sonuçları Tablo 2'de gösterilmiştir.

Tablo 2. Vaka Sayısı ile Altın Fiyatları için Sınır Testi Sonuçları

\begin{tabular}{|c|c|c|c|c|c|c|c|}
\hline \multirow[b]{2}{*}{$\mathbf{k}^{*}$} & \multirow{2}{*}{$\begin{array}{c}\mathbf{F} \\
\text { İstatistiği }\end{array}$} & \multicolumn{2}{|c|}{ \%1 kritik değer } & \multicolumn{2}{|c|}{ \%5 kritik değer } & \multicolumn{2}{|c|}{ \%10 kritik değer } \\
\hline & & Alt Sınır & Üst Sınır & Alt Sınır & Üst Sınır & Alt Sinır & Üst Sınır \\
\hline 1 & 4.21 & 4.94 & 5.58 & 3.62 & 4.16 & 3.02 & 3.51 \\
\hline \multicolumn{8}{|c|}{ Tanısal Denetim İstatistikleri } \\
\hline \multicolumn{4}{|c|}{ Breusch-Godfrey LM Testi } & \multicolumn{4}{|c|}{$1.174(0.325)$} \\
\hline \multicolumn{4}{|c|}{ Jarque Bera Testi } & \multicolumn{4}{|c|}{$1.372(0.506)$} \\
\hline \multicolumn{4}{|c|}{ White Testi } & \multicolumn{4}{|c|}{$0.736(0.695)$} \\
\hline \multicolumn{4}{|c|}{ Ramsey Reset Testi } & \multicolumn{4}{|c|}{$1.709(0.106)$} \\
\hline
\end{tabular}


* Parantez içindeki değerler olasılık değerlerini göstermektedir.

Tablo 2'de görüldüğü üzere hesaplanan F-istatistiği değerinin \%5 kritik değerden (4.21>4.16) büyük olması seriler arasında bir eş bütünleşme ilişkisinin olduğunu göstermektedir. Ayrıca model bütün tanısal denetim istatistiklerinden başarılı bir şekilde geçmiştir. Seriler arasında eş bütünleşme ilişkisinin tespit edilmesinden sonra 3.8 numaralı eşitlik yardımıyla uzun dönem modeli kurulmuş ve uzun dönem katsayıları Tablo 3'de gösterilmiştir.

Tablo 3. Vaka Sayısı ile Altın Fiyatları için Uzun Dönem Katsayıları

\begin{tabular}{|c|c|c|c|c|}
\hline \multicolumn{5}{|c|}{ Uzun Dönem Katsayıları } \\
\hline Değişkenler & Katsayı & Standart Hata & t-istatistik & Olasılık \\
\hline LNCVD & $0.029^{*}$ & 0.003 & 9.478 & 0.000 \\
\hline C & $7.088^{*}$ & 0.039 & 181.822 & 0.000 \\
\hline \multicolumn{7}{|c|}{$\mathrm{R}^{2}=0.876$} & F-istatistik=18.096 & F-istatistik(olasılık)=0.000 & $\mathrm{DW}=2.010$ \\
\hline
\end{tabular}

Tablo 3'de görülen uzun dönem katsayılarına bakıldığı zaman Incvd değişkeninin istatistiki olarak anlamlı ve katsayısının pozitif işaretli olduğu görülmektedir. Bu sonuca göre COVID-19 vaka sayılarındaki \%1'lik bir artışın altın fiyatlarında \%0.029'luk bir artışa neden olabileceği söylenebilir. Bir diğer ifadeyle vaka sayıları ile altın fiyatları arasında uzun dönemde aynı yönlü bir ilişki mevcuttur. Uzun dönem katsayıları tespit edildikten sonra kısa dönemli ilişkiye bakmak için 3.11 numaralı eşitlik yardımıyla kurulan kısa dönem hata düzeltme modeli sonuçları Tablo 4'de gösterilmiştir.

Tablo 4. Vaka Sayısı ile Altın Fiyatları için Kısa Dönem Katsayıları

\begin{tabular}{|c|c|c|c|c|}
\hline Değişkenler & Katsayı & Std. Hata & t-istatistik & Olasılık \\
\hline $\mathrm{D}(\mathrm{LNAF}(-1))$ & $0.665^{*}$ & 0.170 & 3.913 & 0.000 \\
\hline $\mathrm{D}(\mathrm{LNAF}(-2))$ & 0.270 & 0.184 & 1.466 & 0.153 \\
\hline $\mathrm{D}(\mathrm{LNAF}(-3))$ & $0.380^{* *}$ & 0.172 & 2.201 & 0.036 \\
\hline $\mathrm{D}(\mathrm{LNAF}(-4))$ & 0.270 & 0.188 & 1.435 & 0.162 \\
\hline $\mathrm{D}(\mathrm{LNCVD})$ & -0.007 & 0.063 & -0.111 & 0.912 \\
\hline $\mathrm{D}(\mathrm{LNCVD}(-1))$ & -0.046 & 0.053 & -0.857 & 0.398 \\
\hline $\mathrm{D}(\mathrm{LNCVD}(-2))$ & $0.204^{*}$ & 0.054 & 3.778 & 0.000 \\
\hline $\mathrm{D}(\mathrm{LNCVD}(-3))$ & 0.017 & 0.061 & 0.289 & 0.774 \\
\hline $\mathrm{D}(\mathrm{LNCVD}(-4))$ & $0.164^{*}$ & 0.057 & 2.830 & 0.008 \\
\hline ECT(-1) & $-0.674^{*}$ & 0.183 & -3.679 & 0.001 \\
\hline $\mathrm{R}^{2}=0.504$ & F-istatistik=18.096 F-istatistik(olasılık)=0.000 DW=2.010 \\
\hline$*{ }^{* *},{ }^{* * *}$ sırasıyla değişkenlerin \%1, \%5 ve \%10 anlamlılık düzeylerinde anlamlı olduğunu göstermektedir.
\end{tabular}

Tablo 4' de ki sonuçlara göre altın fiyatları değişkeni ile yine kendisinin bir ve üç gecikmeli değerleri arasında pozitif ve istatistiki olarak anlamlı bir ilişki bulunmuştur. COVID-19 vaka sayıları değişkeninin iki ve dört gecikmeli değerler ile altın fiyatları değişkeni arasında pozitif ve istatistiki olarak anlamlı bir ilişki bulunmuştur. Bir diğer ifadeyle kısa dönem sonuçlarının uzun dönem sonuçlarını desteklediği ve kısa dönemde vaka sayıları ile altın fiyatları arasında aynı yönlü bir ilişki olduğu söylenebilir. Ayrıca hata terimi beklenildiği gibi negatif ve istatistiki olarak anlamlı bulunmuştur. Bu sonuca göre kısa dönemde meydana çıkan herhangi bir uzun dönem denge sapmasının \%67'si bir sonraki dönemde düzeltilmektedir. 


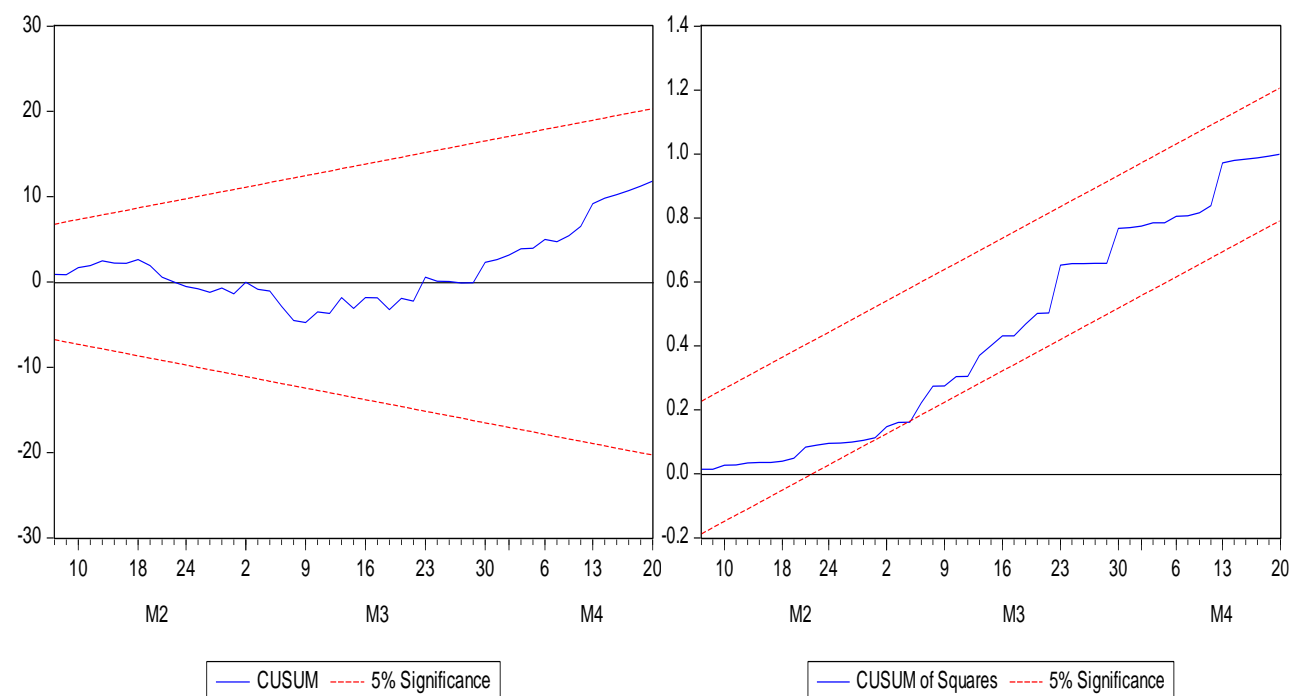

Şekil 2. Vaka Sayısı ve Altın Fiyatları İçin Cusum ve Cusumq Sonuçları

Şekil 2 incelendiğinde, CUSUM ve CUSUMQ istatistiklerinin, \%5 anlam düzeyini belirten kritik sınırları arasında kaldığı görülmektedir. Dolayısıyla her hangi bir yapısal kırılmanın olmadığı ve $\operatorname{ARDL}(5,5)$ modelinden elde edilen katsayıların istikrarlı olduğu görülmektedir.

Akaike Bilgi Kriteri

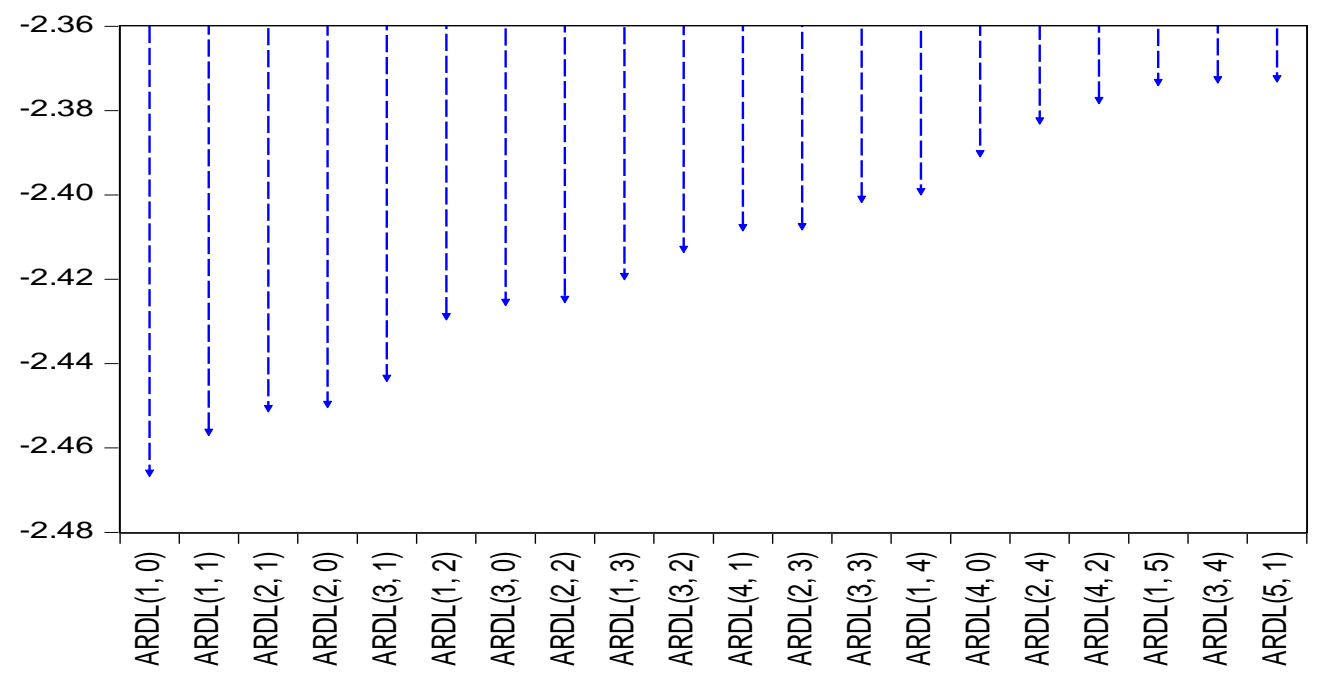

Şekil 3. Petrol Fiyatları - COVID-19 Modeli İçin Uygun Gecikme Uzunluğu

Şekil 3'de petrol fiyatları ile COVID-19 vaka sayıları arasındaki eşbütünleşme ilişkisine bakmak için yararlandığımız 3.6 numaralı eşitlik için bulunan uygun gecikme uzunlukları gösterilmiştir. Buna göre Akaike bilgi kriteri değeri en düşük olan ARDL $(1,0)$ modeli en uygun model olarak belirlenmiştir.

Gecikme uzunlukları belirlendikten sonra 3.6 numaralı eşitlik yardımıyla Sınır Testi analizi yapılmıştır. Analiz sonuçları Tablo 5. de gösterilmiştir.

Tablo 5. Vaka Sayısı ile Petrol Fiyatları için Sınır Testi Sonuçları

\begin{tabular}{|c|c|c|c|c|c|c|c|}
\hline & $\mathbf{F}$ & \multicolumn{2}{|c|}{ \%1 kritik değer } & \multicolumn{2}{c|}{ \%5 kritik değer } & \multicolumn{2}{c|}{ \%10 kritik değer } \\
\cline { 3 - 8 } $\mathbf{k}^{*}$ & İstatistiği & Alt Sınır & Üst Sınır & Alt Sınır & Üst Sınır & Alt Sınır & Üst Sınır \\
\hline 1 & 1.25 & 4.94 & 5.58 & 3.62 & 4.16 & 3.02 & 3.51 \\
\hline
\end{tabular}




\begin{tabular}{|c|c|}
\hline \multicolumn{2}{|c|}{ Tanısal Denetim İstatistikleri } \\
\hline Breusch-Godfrey LM Testi & $0.820(0.4461)$ \\
\hline Jarque Bera Testi & $48.665(0.000)$ \\
\hline White Testi & $1.819(0.171)$ \\
\hline Ramsey Reset Testi & $7.423(0.008)$ \\
\hline
\end{tabular}

* Parantez içindeki değerler olasılık değerlerini göstermektedir.

Tablo 5.'de görüldüğü üzere hesaplanan F-istatistiği değerinin \%10 alt sınır kritik değerden (3.02>1.25) küçük olması seriler arasında bir eş bütünleşme ilişkisinin olmadığını göstermektedir. Değişkenler arasında uzun dönem ilişkisi bulunamadığından dolayı uzun ve kısa dönem katsayıları tespit edilmemiştir.

Akaike Bilgi Kriteri

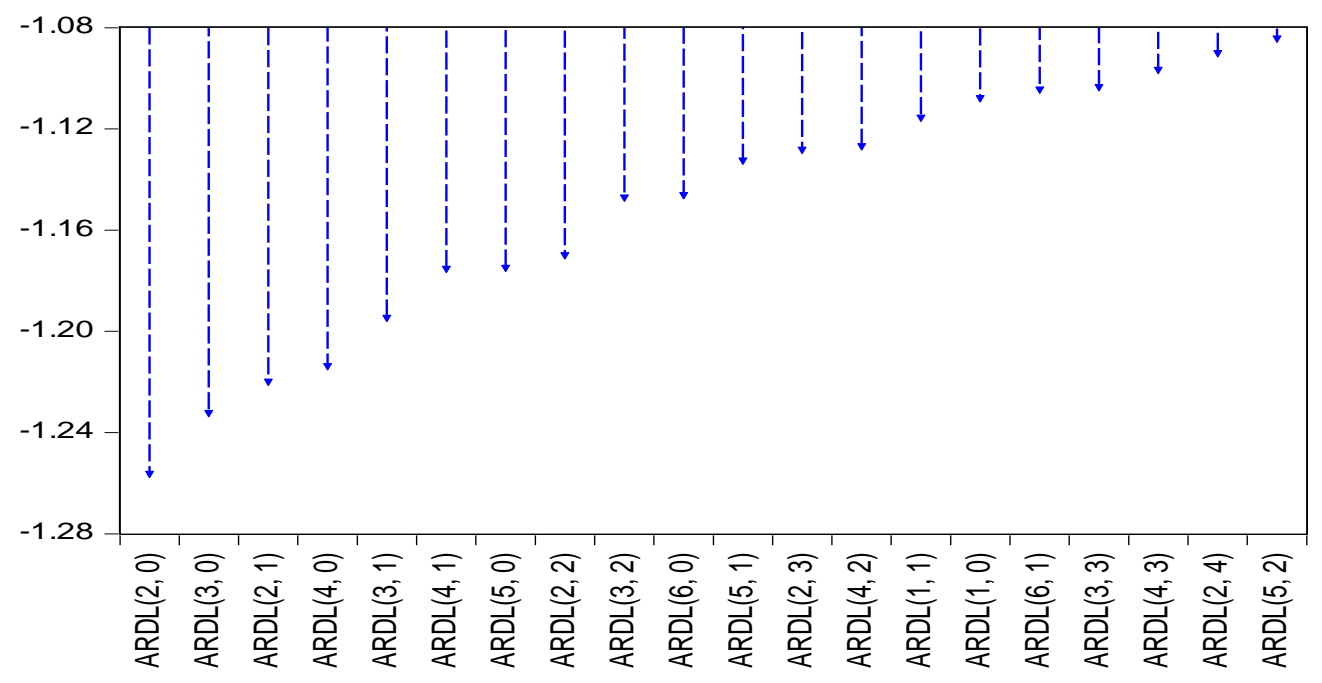

Şekil 4. VIX Endeksi - COVID-19 Modeli iç̧in Uygun Gecikme Uzunluğu

Şekil 4'te VIX Endeksi ile Covid -19 vaka sayıları arasındaki eşbütünleşme ilişkisine bakmak için yararlandığımız 3.7 numaralı eşitlik için bulunan uygun gecikme uzunlukları gösterilmiştir. Buna göre Akaike bilgi kriteri değeri en düşük olan ARDL $(2,0)$ modeli en uygun model olarak belirlenmiştir.

Gecikme uzunlukları belirlendikten sonra 3.7 numaralı eşitlik yardımıyla Sınır Testi analizi yapılmıştır. Analiz sonuçları Tablo 6'da gösterilmiştir.

Tablo 6. Vaka Sayısı ile VIX Endeksi için Sınır Testi Sonuçları

\begin{tabular}{|c|c|c|c|c|c|c|c|}
\hline \multirow[b]{2}{*}{$\mathbf{k}^{*}$} & \multirow{2}{*}{$\begin{array}{c}\mathbf{F} \\
\text { İstatistiği }\end{array}$} & \multicolumn{2}{|c|}{ \%1 kritik değer } & \multicolumn{2}{|c|}{ \%5 kritik değer } & \multicolumn{2}{|c|}{ \%10 kritik değer } \\
\hline & & Alt Sınır & Üst Sınır & Alt Sınır & Üst Sınır & Alt Sınır & Üst Sınır \\
\hline 1 & 7.65 & 4.94 & 5.58 & 3.62 & 4.16 & 3.02 & 3.51 \\
\hline \multicolumn{8}{|c|}{ Tanısal Denetim İstatistikleri } \\
\hline \multicolumn{4}{|c|}{ Breusch-Godfrey LM Testi } & \multicolumn{4}{|c|}{$0.470(0.629)$} \\
\hline \multicolumn{4}{|c|}{ Jarque Bera Testi } & \multicolumn{4}{|c|}{$2.573(0.276)$} \\
\hline \multicolumn{4}{|c|}{ White Testi } & \multicolumn{4}{|c|}{$1.819(0.171)$} \\
\hline \multicolumn{4}{|c|}{ Ramsey Reset Testi } & \multicolumn{4}{|c|}{$2.179(0.126)$} \\
\hline
\end{tabular}

* Parantez içindeki değerler olasılık değerlerini göstermektedir. 
Tablo 6'da görüldüğü üzere hesaplanan F-istatistiği değerinin \%1 üst sınır kritik değerinden (7.65>5.58) büyük olması seriler arasında \%1 önem düzeyinde bir eş bütünleşme ilişkisinin olduğunu göstermektedir. Ayrıca model bütün tanısal denetim istatistiklerinden başarılı bir şekilde geçmiştir. Seriler arasında eş bütünleşme ilişkisinin tespit edilmesinden sonra 3.10 numaralı eşitlik yardımıyla uzun dönem modeli kurulmuş ve uzun dönem katsayıları Tablo 7'de gösterilmiştir.

Tablo 7. Vaka Sayısı ile VIX Endeksi için Uzun Dönem Katsayıları

\begin{tabular}{|c|c|c|c|c|}
\hline \multicolumn{5}{|c|}{ Uzun Dönem Katsayıları } \\
\hline Değişkenler & Katsayı & Standart Hata & t-istatistik & Olasılık \\
\hline LNCVD & $0.309^{* *}$ & 0.127 & 2.437 & 0.020 \\
\hline C & $6.889^{*}$ & 1.671 & 4.124 & 0.001 \\
\hline \multicolumn{2}{|c|}{$R^{2}=0.842$} & F-istatistik=63.922 & F-istatistik(olasılık) $=0.000 \quad$ DW=1.993 \\
\hline
\end{tabular}

* Parantez içindeki değerler olasılık değerlerini göstermektedir.

Tablo 7'de görülen uzun dönem katsayılarına bakıldığı zaman Incvd değişkeninin istatistiki olarak anlamlı ve katsayısının pozitif işaretli olduğu görülmektedir. Bu sonuca göre COVID-19 vaka sayılarındaki \%1'lik bir artışın VIX Endeksinde \%0.309'luk bir artışa neden olabileceği söylenebilir. Bir diğer ifadeyle vaka sayıları ile VIX Endeksi arasında uzun dönemde aynı yönlü bir ilişki olduğu söylenebilir. Uzun dönem katsayıları tespit edildikten sonra kısa dönemli ilişkiye bakmak için 3.13 numaralı eşitlik yardımıyla kurulan kısa dönem hata düzeltme modeli sonuçları Tablo 8'de gösterilmiştir.

Tablo 8. Vaka Sayısı ile VIX Endeksi için Kısa Dönem Katsayıları

\begin{tabular}{|c|c|c|c|c|}
\hline Değişkenler & Katsayı & Std. Hata & t-istatistik & Olasılık \\
\hline $\mathrm{D}($ LNVIX(-1)) & $-0.391^{*}$ & 0.130 & -3.010 & 0.005 \\
\hline $\mathrm{D}(\mathrm{LNCVD})$ & $0.135^{*}$ & 0.037 & 3.651 & 0.001 \\
\hline $\mathrm{ECT}(-1)$ & $-0.193^{*}$ & 0.040 & -4.924 & 0.000 \\
\hline $\mathrm{R}^{2}=0.421$ & F-istatistik=63.922 & F-istatistik(olasılık)=0.000 DW=1.993 \\
\hline$*, * *, * * *$ sırasıyla değişkenlerin \%1, \%5 ve \%10 anlamlılık düzeylerinde anlamlı olduğunu göstermektedir.
\end{tabular}

Tablo 8' de ki sonuçlara göre VIX Endeksi değişkeni ile yine kendisinin bir gecikmeli değeri arasında negatif ve istatistiki olarak anlamlı bir ilişki bulunmuştur. COVID-19 vaka sayıları değişkeninin düzey değeri ile VIX Endeksi değişkeni arasında pozitif ve istatistiki olarak anlamlı bir ilişki tespit edilmiştir. Bir diğer ifadeyle kısa dönem sonuçlarının uzun dönem sonuçlarını desteklediği ve kısa dönemde vaka sayıları ile VIX Endeksi arasında aynı yönlü bir ilişki olduğu söylenebilir. Ayrıca hata terimi beklenildiği gibi negatif ve istatistiki olarak anlamlı bulunmuştur. Bu sonuca göre kısa dönemde meydana çıkan herhangi bir uzun dönem denge sapmasının \%19’u bir sonraki dönemde düzeltilmektedir. 

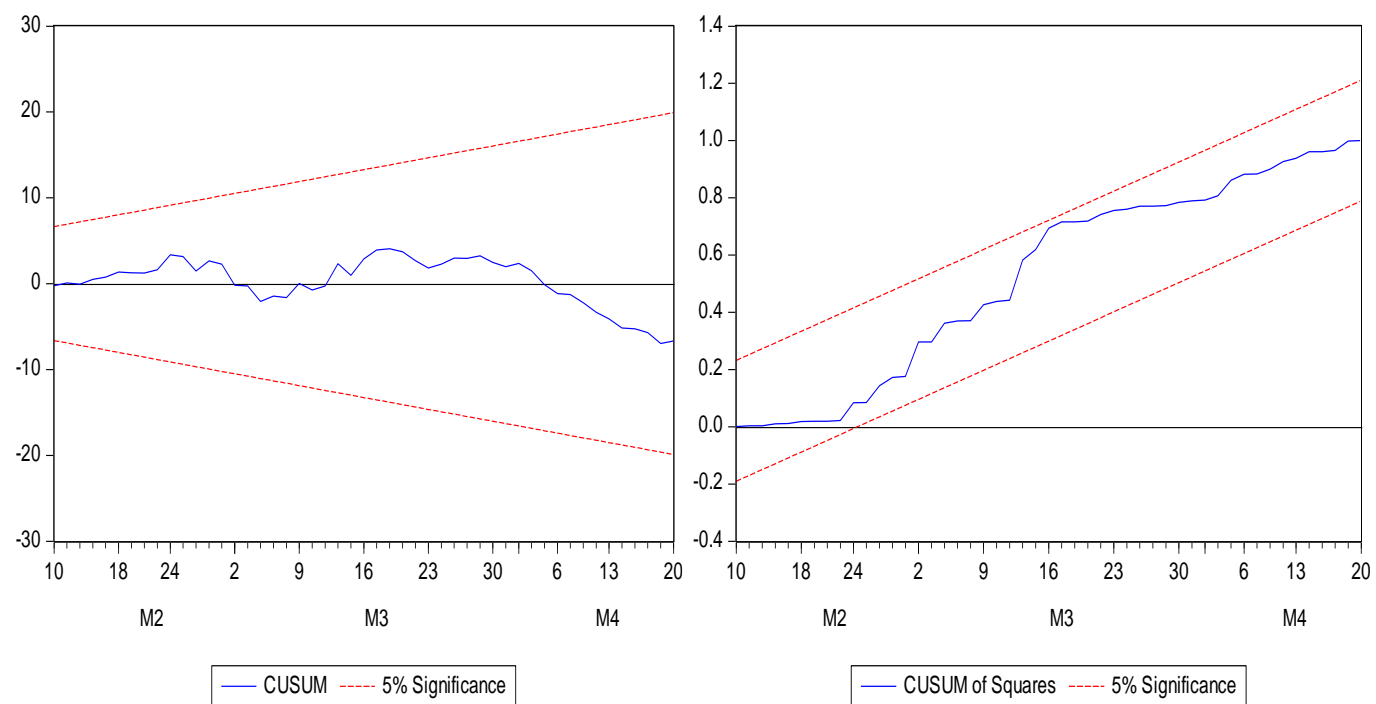

Şekil 5. Vaka Sayısı ve VIX Endeksi için Cusum ve Cusumq Sonuçları

Şekil 5'de ki CUSUM ve CUSUMQ sonuçları incelendiğinde, modelde her hangi bir yapısal kırılmanın olmadığı ve ARDL $(2,0)$ modelinden elde edilen katsayıların istikrarlı olduğu görülmektedir.

\section{SONUÇ VE DEĞERLENDIRME}

Illk olarak 2019 yılının Aralık ayında Çin'de görülen ve sonrasında tüm dünyaya yayılan COVID-19 12 Mart 2020'de Dünya Sağlık Örgütü tarafından salgın hastalık olarak ilan edilmiştir. Vaka ve ölüm sayılarının her geçen gün arttığı görülmektedir. 27 Nisan 2020 tarihi verilerine göre dünyada 211449 insanın hayatını kaybetmesine neden olan bu virüs ülkelerin ekonomilerini ciddi şekilde etkileyerek tüm sektörleri dolaylı ve dolaysız olarak sıkıntıya sokmuştur. Finansal piyasalarda yaşanan bu olumsuzluklardan payını almıştır. Dünyada söz sahibi olan ekonomilerin borsalarında ciddi düşüler yaşanmış bu durum finansal aktörlerin yaşadıkları korkudan dolayı güvenli gördükleri farklı yatııım araçlarına yönelmelerine neden olmuştur. Bu çalışmada 22 Ocak 2020 - 20 Nisan 2020 döneminde küresel boyutta COVID-19 salgın hastalığı görülen vaka sayıları ile altın fiyatları, petrol fiyatları ve VIX Endeksi arasındaki kısa ve uzun dönemli ilişki araştırılmıştır.

Altının ons fiyatı 2012 Aralık ayından beri en yüksek seviyesini görerek COVID-19 salgını sürecinde 2020 Mart ayında 1736 dolara kadar artış gösterdi. Brent petrol ise 1999 Ocak ayından bu yana en düşük seviyesini görerek 2020 Mart ayında 21 dolara kadar düşüş gösterdi. VIX Endeksi ise 2008 Ekim ayındaki seviyesini de geçerek tüm zamanların en yüksek değerine ulaştı.

ARDL Sınır Testi kullanılarak yapılan analizde COVID-19 günlük vaka sayıları ile emtia piyasasında yer alan altın fiyatları arasında aynı yönlü ilişki tespit edilmiştir. COVID-19 salgını sürecinde altın fiyatlarının vaka sayısına olumlu tepki vermesi piyasalarda yaşanan belirsizliği ortaya koymaktadır. Artan vaka ve ölüm sayıları küresel olarak ekonomideki gidişatı olumsuz etkilemekte ve salgının yoğun yaşandığı ülkelerin savunmasız olduklarını göstermektedir. Finansal aktörler kendilerini güvende hissettikleri emtialardan olan altına yönelmektedirler.

Analizde COVID-19 günlük vaka sayıları ile emtia piyasasında yer alan petrol fiyatları arasında herhangi bir eşbütünleşme tespit edilememiştir. COVID-19 öncesinde başlayan ve devam eden OPEC Ülkeleri ve Rusya arasındaki petrol fiyatı krizinden dolayı petrol fiyatlarında düşüş yaşanmıştı. Bu süreçte COVID-19 salgını da Avrupa ve Amerika gibi dünya ekonomisinde 
söz sahibi ülkelerde artış gösterdikçe petrol fiyatlarında düşüş artmaya devam etti. Sansa (2020)' da çalışmamızla uyumlu şekilde COVID-19 onaylı vakaların Çin'de 20 Ocak 2020 - 23 Şubat 2020 tarihli dönemden itibaren benzin fiyatlarına olumsuz ve önemsiz bir etkisi olduğunu ortaya koyulmuştur. Her ne kadar çalışmada eşbütünleşme ilişkisi hem kısa vadede hem uzun vadede bulunamasa da COVID-19 dönemi süresince yaşanan petrol fiyatları düşüşü ele alınarak petrol fiyatlarında yaşanan bu belirsizliklerden dolayı finansal aktörlerin yatırım yaparken dikkatli olması gerekmektedir. Alternatif yatırım araçlarını da dikkate alıp süreci kayıp yaşamadan atlatmak için porföylerini oluşturmaları önerilmektedir.

Son olarak analizde COVID-19 vaka sayılarının VIX Endeksini önemli derecede etkilediği gösterilmiştir. Bu çalışmayla parelel olarak Onali (2020) çalışmasında İtalya ve Fransa'da bildirilen ölüm sayısının VIX getirileri üzerinde olumlu bir etkisi olduğunu göstermiştir. COVID19 salgınıyla yaşanan süreçte finansal oynaklıkta artış yaşanmış, VIX Endeksi tarihi rekor seviyelere yükselmiştir. Finansal aktörler VIX Endeksini izleyerek piyasalardaki korku hakkında fikir sahibi olmakta ve buradan hareketle gelecek için yatırım yapma düşüncesi içine girmektedirler. Finansal piyasalarda ise tarihi dalgalanmaların yaşandığı bu salgın sürecinde yatırımcıların doğru karar almasında VIX Endeksi verilerinin yararlı olacağı ortaya koyulmuştur.

COVID-19 salgın hastalığının finansal piyasalar ve emtia piyasaları üzerindeki etkisini inceleyen çalışmaların artması finansal aktörlerin işini kolaylaştıracaktır. Başarılı sonuçlar alınabileceği düşüncesinden yola çıkılarak küresel ekonomide yaşanan belirsizliği gösteren ve çözüm öneren çalışmaların ülke farklııkları, sektör farklıııları, piyasa farklılıkları ile daha çeşitlilik kazandırılarak yapılmasının literatüre katkı sağlaması beklenmektedir. 


\section{REFERENCES/KAYNAKÇA}

AÇIKGÖZ, Ö., \& GÜNAY, A. (2020). The early impact of the Covid-19 pandemic on the global and Turkish economy. Turkish Journal of Medical Sciences, 50(SI-1), 520-526.

ALBULESCU, C. (2020a). Coronavirus and oil price crash. Available at SSRN 3553452.

AKERLOF, A. ve ARON, J. (2000). Limonlar için piyasa. New Jersey: Oxford Press.

ALBULESCU, C. (2020b). Coronavirus and financial volatility: 40 days of fasting and fear. arXiv preprint arXiv:2003.04005.

BAKER, S., BLOOM, N., DAVIS, S. J., KOST, K., SAMMON, M., \& VIRATYOSIN, T. (2020). The unprecedented stock market reaction to Covid-19. Covid Economics: Vetted and RealTime Papers, 1(3).

BALDWIN, R., \& TOMIURA, E. (2020). Thinking ahead about the trade impact of Covid-19. Economics in the Time of COVID-19, 59.

BARDSEN, G. (1989). "Estimation of long run coefficients in error correction models". Oxford Bulletin of Economics and Statistics, 51(3), 345-350.

BECK, T. (2020). 6 Finance in the times of coronavirus. Economics in the Time of COVID-19, 73.

BEUTELS, P., JIA, N., ZHOU, Q. Y., SMITH, R., CAO, W. C., \& DE VLAS, S. J. (2009). The economic impact of SARS in Beijing, China. Tropical Medicine \& International Health, 14, 85-91.

BLOOM, D. E., \& MAHAL, A. S. (1997). Does the AIDS epidemic threaten economic growth?. Journal of Econometrics, 77(1), 105-124.

EICHENBAUM, M. S., REBELO, S., \& TRABANDT, M. (2020). The macroeconomics of epidemics (No. w26882). National Bureau of Economic Research.

ERIK, B., LOMBARDI, M. J., MIHALJEK, D., \& SHIN, H. S. (2020). The dollar, bank leverage and real economic activity: an evolving relationship.

FOSU, E. O. ve MANGUS, F. (2006). "Bounds Testing Approach to Cointergration: An Examination of Foreign Direct Investment, Trade and Growth Relationship". Journal of American Applied Science, 3(11), 2079-2085.

KEOGH-BROWN, M. R., \& SMITH, R. D. (2008). The economic impact of SARS: how does the reality match the predictions?. Health policy, 88(1), 110-120.

LUO, S., \& TSANG, K. P. (2020). How Much of China and World GDP Has The Coronavirus Reduced?. Available at SSRN 3543760.

MAKRIDIS, C., \& HARTLEY, J. (2020). The Cost of COVID-19: A Rough Estimate of the 2020 US GDP Impact. Special Edition Policy Brief.

ONALI, E. (2020). COVID-19 and stock market volatility. Available at SSRN 3571453.

ÖZATAY, F., \& SAK, G. (2020). COVID-19'un Ekonomik Sonuçlarını Yönetebilmek İçin Ne Yapılabilir?. TEPAV Politika Notu, (202005). 
PESARAN, M. H. ve SHIN, Y. (1998). “An autoregressive distributed-lag modelling approach to cointegration analysis". Econometric Society Monographs. 31, 371-413.

PESARAN, M. H., SHIN, Y., \& SMITH, R. J. (2001). "Bounds testing approaches to the analysis of level relationships". Journal of applied econometrics. 16(3), 289-326.

SANSA, N. A. (2020). Analysis for the Impact of the Covid-19 to the Petrol Price in China. Available at SSRN 3547413.

ŞENOL, Zekai, \& ZEREN, Feyyaz (2020), Coronavirus (COVID-19) And Stock Markets: The Effects Of The Pandemic On The Global Economy. Avrasya Sosyal ve Ekonomi Araştırmaları Dergisi, 7(4), 1-16.

TABAN, S. (2008). "Türkiye'de Enflasyon-Ekonomik Büyüme İlişkisi: Sinir Testi Yaklaşımı". Türkiye İstatistik Kurumu Akademi, 3(5), 145-167.

WAGNER, A. F. (2020). What the stock market tells us about the post-COVID-19 world. Nature Human Behaviour, 1-1.

ZEREN, F., \& HIZARCI, A. The Impact Of COVID-19 Coronavirus On Stock Markets: Evidence From Selected Countries. Muhasebe ve Finans incelemeleri Dergisi, 3(1), 78-84.

https://tr.investing.com

https://www.worldometers.info 


\section{EXTENDED SUMMARY}

\section{Aim and Scope}

COVID-19 Coronavirus continues to spread rapidly in dozens of countries. As of April 25, 2020, there are approximately 3 million confirmed cases of COVID-19 and 203164 deaths in more than 150 countries. By showing the effect of COVID-19 Coronavirus epidemic disease on gold and oil and VIX Index as of January 22, 2020, this study aims to provide an evidence to guide financial market actors in this process in which difficult times are experienced for the whole World.

\section{Methods}

According to the unit root test results, ARDL Boundary Test method was used because the variables were stationary at different levels, that is, some of the variables were I (0) and some were I (1). The analyzes were made through the Eviews package program.

\section{Findings}

This study was carried out between January 22, 2020 and April 20, 2020 using daily data. According to the results of the analysis, a similar relationship has been determined between the number of cases and gold prices. Similarly, a similar direction was found between the number of cases and the VIX Index. However, no co-integration relationship could be determined between the number of cases and oil prices.

\section{Conclusion}

In the analyzes, the short and long term relationship between the number of cases with COVID19 Coronary virus epidemic disease and gold prices, oil prices and VIX Index was investigated. The positive reaction of gold prices to the number of cases reveals the uncertainty experienced in the markets. As the COVID-19 Coronavirus outbreak increased in countries which are dominant in the world economy, such as European countries and America, the decline in oil prices accelerated. Due to these uncertainties in oil prices, financial actors need to be careful while making investments. In the process experienced with COVID-19 Coronavirus epidemic, financial volatility increased, and the history of VIX Index rose to record levels. Financial actors have an idea about the fear in the markets by watching the VIX Index and therefore they have the idea of investing for the future. 